IZA DP No. 9133

Estimating the External Returns to Education:

Evidence from China

Wen Fan

Yuanyuan $\mathrm{Ma}$

Liming Wang

June 2015 


\title{
Estimating the External Returns to Education: Evidence from China
}

\author{
Wen Fan \\ Yuanyuan Ma \\ Trinity College Dublin \\ and IZA \\ Liming Wang \\ University College Dublin
}

Nanjing University of Finance and Economics

Discussion Paper No. 9133
June 2015

IZA

P.O. Box 7240

53072 Bonn

Germany

Phone: +49-228-3894-0

Fax: +49-228-3894-180

E-mail: iza@iza.org

Any opinions expressed here are those of the author(s) and not those of IZA. Research published in this series may include views on policy, but the institute itself takes no institutional policy positions. The IZA research network is committed to the IZA Guiding Principles of Research Integrity.

The Institute for the Study of Labor (IZA) in Bonn is a local and virtual international research center and a place of communication between science, politics and business. IZA is an independent nonprofit organization supported by Deutsche Post Foundation. The center is associated with the University of Bonn and offers a stimulating research environment through its international network, workshops and conferences, data service, project support, research visits and doctoral program. IZA engages in (i) original and internationally competitive research in all fields of labor economics, (ii) development of policy concepts, and (iii) dissemination of research results and concepts to the interested public.

IZA Discussion Papers often represent preliminary work and are circulated to encourage discussion. Citation of such a paper should account for its provisional character. A revised version may be available directly from the author. 


\title{
ABSTRACT \\ Estimating the External Returns to Education: Evidence from China
}

\begin{abstract}
Using longitudinal data from the China Health and Nutrition Survey, we examine how individual wages change in line with the share of college graduates in a given province. The individual fixed effect model shows that the external returns to education in China appear to be zero. We estimate an instrumental variables fixed effects model where share of college graduates is instrumented by the number of universities with special status and find positive external returns to education of about 10 per cent to 14 per cent. We also find that the returns are affected by individual heterogeneity. While negligible returns are found for urban, women, and high-educated workers, the returns are positive and statistically significant for rural, men, and low-educated workers. This finding provides the motivation for increasing education investment in rural China and targeting it more toward poorly educated workers.
\end{abstract}

JEL Classification: J0, J24, O15

Keywords: education, public investment, externalities, China

Corresponding author:

Yuanyuan Ma

The Irish Longitudinal Study on Ageing (TILDA)

Lincoln Gate

Trinity College Dublin

Dublin 2

Ireland

E-mail: mayu@tcd.ie

\footnotetext{
* The authors acknowledge the UNC California Population Centre for granting access to the CHNS data. Fan gratefully acknowledges financial support from the Priority Academic Program Development of Jiangsu Higher Education Institutions (PAPD).We thank participants in the 2013 Korean Association for Policy Studies (KAPS) Summer and International Conference, the $16^{\text {th }}$ IZA Summer School in Labour Economics, 2012 European Doctoral Group in Economics (EDGE) Jamboree, the 2012 Irish Society of New Economists (ISNE) Conference, and the Development Roundtable in Geary Institute for helpful comments. We also thank Paul Devereux, Patrick Paul Walsh, Frank Walsh, Xiaobo He and $\mathrm{CHO}$ Minhyo for helpful conversations and comments. We are responsible for all remaining errors.
} 


\section{Introduction}

A good understanding of human capital externalities is important for both policy makers and social science researchers. While much attention has been devoted to the empirical investigation of the role of human capital in the process of economic growth and development at the aggregate level (Lucas 1998), the relevant work at the individual level seems to be inadequate. Education, one measure of human capital in empirical work, is usually used for such studies. There are at least two reasons why people care about the effect of human capital externality, i.e. external returns to education. Firstly, current education policies are often justified on the basis of at least modest human-capital externalities, a better understanding of which would produce important implications or even guidelines for policy making. Secondly, the magnitude of the external returns to education is important for assessing the efficiency of public investment in education.

Economists have speculated for at least a century that the social returns to education may exceed the private returns (Moretti 2004). However, most of these studies on education externality focus on the developed countries. In this paper, we attempt to contribute to the existing literature with new evidence on the external returns to education in China, an important developing economy in the world, and hope to shed more light on the cross-country income differential via the human capital externality perspective.

Since the Reform and Open-door policy implemented in 1978, China has gradually altered its attitude toward education by realizing the significant impact of education on economic growth and social development. From 1980 onward, the total investment in education and the government's investment in education have continued to increase drastically. In 1980, the educational investment from government was 11.42 billion Yuan, and the investment in education from other sources (charity, social donation, etc.) was almost negligible. In 2009, the education investment from government increased to 1,223 billion Yuan, and the total investment in education rose to 1,650 billion Yuan. Even taking inflation into account, this is still a huge increase. ${ }^{1}$ Although the investment

\footnotetext{
${ }^{1}$ China Statistical Yearbooks.
} 
from other sources became increasingly visible, the government is still the dominant body for education investment.

Nonetheless, when compared to the striking GDP growth, it is not surprising that criticisms exist that the Chinese government's investment in education is far from satisfactory. Figure 1 shows the GDP and the government's investment in education (in current billion RMB) in China from 1980 to 2009. Compared with the rapid growth of the absolute value of investment, the proportion of the government's education investment in GDP during the same period is relatively stable. Also, the magnitudes of the proportion in China are much smaller than they are in the developed world during the same period. Figure 2 shows the international comparison. However, we argue that it may be quite hasty to judge whether the government's investment in education is sufficient or not before fully understanding the essence of education. Education is a semi-public good with both private and external returns. Although there is a large body of literature investigating the private returns to education in China, there has been little focus on the education externalities. In this paper, we attempt to answer a number of questions related to the external returns to education. These include whether China has a positive education externality like most developed countries; the extent of the externality, if it exists; and most importantly, what can be learnt from questioning China's external returns to education.

In this paper, we examine how individual wages change in line with the share of college graduates in a given province using longitudinal data from China Health and Nutrition Survey (CHNS). ${ }^{2}$ In conventional fixed effects (FE) estimates, insignificant coefficients suggest that the external returns to education are almost zero. However, when we account for the endogeneity problem and then implement instrumental variables fixed effects estimates, we find positive external returns to education for full sample of about 10 per cent to 14 per cent.

Taking individual heterogeneity into consideration, we split our sample by region, gender, and education levels. While negligible returns are found for urban, women, and

\footnotetext{
${ }^{2}$ We describe this dataset in details in section 3.1.
} 
high-educated workers, the returns are positive and statistically significant for rural, men, and low-educated workers. This finding provides the motivation for increasing education investment in rural China and targeting it more toward poorly educated workers.

The layout of this paper is as follows. In section 2, we review the relevant literature. Section 3 presents data and methodology. Section 4 provides the main empirical results, and section 5 offers further discussions. Section 6 concludes.

\section{Literature Review}

Marshall (1961) argues that increasing the geographic concentration of specialized inputs increases productivity because the matching between factor inputs and industries is improved. Therefore, firms find it profitable to invest in new technologies only when there is a sufficient supply of trained workers to replace those employees who leave. Greater human capital encourages more investment by firms and raises other workers' wages via this channel.

On the other hand, if we believe the knowledge spillover story in which the sharing of knowledge and skills through formal and informal interaction may generate positive externality across workers, living with more educated people would make you earn more. In contrast, if the school does not further education but just helps workers with a college degree to identify themselves from those without one, signalling theory tells us that the external returns to education tend to be very low, even zero. (Acemoglu 1996; Acemoglu and Angrist 2000)

Furthermore, people could find negative external returns to education if labour supply greatly exceeds demand and then crucial competition may induce a decrease in individual wages when workers have to face much stronger competitors. (Moretti 2004)

In empirical research, Rauch (1993) is the first attempt to estimate human-capital externalities, finding that the externalities are on the order of 3 per cent to 5 per cent in the United States. Moretti (2004) also finds significant external returns to education using the American National Longitudinal Survey of Youths and American Census data. 
Both of these studies use college share as a parameter of interest. When using average schooling as an alternative, Acemoglu and Angrist (2000) find little evidence with the 1950-1990 American Census data.

Using industry level data, Kirby and Riley (2008) estimate the external returns to schooling in the United Kingdom for the period 1994-2004. They find that for men aged 30-49, a one-year increase in the industry average level of schooling is associated with an increase in individual wages of 2.6 per cent to 3.9 per cent.

Liu (2007) provides the first set of estimates on the external returns to education in Chinese cities. The Two-stage Least Squared (2SLS) estimates indicate that a one-year increase in city average education could increase individual earnings by 11 per cent to 13 per cent, whereas one percentage increase in college share would increase wages by about 1 per cent. Given that he finds over ten times larger external returns using average schooling than using college share, the huge difference prompts us to revisit the issue. Our study differs in at least two strands.

Firstly, while Liu (2007) uses cross-sectional data in his analysis, our paper aims to be the first attempt using longitudinal data. By virtue of the panel element, we are able to get rid of many noises caused by individual unobservables and avoid potential bias with simpler cross-sectional specifications.

Secondly, while Liu (2007) only looks at cities, our study covers both urban and rural areas. Since more than 50 per cent of the Chinese population live in the rural areas, our study tends to be more informative thanks to the more representative samples. ${ }^{3}$ In addition, exploring regional heterogeneity enables us to understand and explain different social phenomena in urban and rural areas and also helps to contribute to pragmatic policy implications, especially on education investment.

In practice, we motivate the individual fixed effects (FE) estimates and examine how individual wages change in line with the share of college graduates in a given province over time. Unlike Liu (2007), we find that one percentage increase in the share of college graduates would increase individual earnings by about 10 per cent to 14 per cent.

\footnotetext{
${ }^{3}$ China Statistical Yearbook, 2011.
} 


\section{Data and Methodology}

\subsection{Data}

The data used in this paper come from the China Health and Nutrition Survey (CHNS), the largest micro-level survey for current China. Starting in 1989, CHNS is an ongoing open cohort, international collaborative project between the Carolina Population Centre at the University of North Carolina at Chapel Hill and the National Institute of Nutrition and Food Safety at the Chinese Centre for Disease Control and Prevention.

CHNS covers nine provinces (Guangxi, Guizhou, Heilongjiang, Henan, Hubei, Hunan, Jiangsu, Liaoning, and Shangdong), which vary considerably in geographic characteristics and economic development levels. A multistage, random cluster process was used to draw the sample surveyed in each of the provinces.

Some macro level information (e.g. the provincial share of college graduates, GDP per capita, lag average adjacent provincial wage, provincial education expenditure, number of universities and colleges per province, number of high school graduates per province, and four-year-ago university/college enrolments), is obtained from China Statistical Year Books. ${ }^{4}$

Starting in 1989, the survey takes place every two to four years. Based on the original longitudinal dataset, we extract an unbalanced panel covering the years 1991, 1997, 2000, 2004, 2006, and 2009. ${ }^{5}$

Figures 3 and 4 are two graphs that depict the correlation between individuals' wage (Log monthly wage) and the share of college graduates by province in 1991 and 2009, respectively. It is clear to see that while the correlation curve appears to be very flatsloping for the year 1991, it turns out to be evidently positive almost 20 years later. This

\footnotetext{
${ }^{4}$ The variable "lag average adjacent provincial wage" refers to the one-year lag of the average wages in adjacent provinces within that region. The nine provinces surveyed cover the four regions - north eastern (Liaoning and Heilongjiang), south eastern (Shangdong and Jiangsu), middle areas (Henan, Hubei and Hunan) and western areas (Guangxi and Guizhou). Similar economic and cultural backgrounds and close distance make labour migrations more likely to occur across provinces within region. As a result, skilled workers are likely to move to the adjacent provinces when there are better job offers. Thus, this variable enables us to control for migration effects.

${ }^{5}$ Years 1989 and 1994 are excluded because no information on the provincial share of college graduates can be matched for these two years.
} 
visual comparison suggests that the wages are higher in areas where the labour force is better educated and encourages us to further investigate whether this correlation is causal.

\subsection{Empirical Strategy}

The baseline individual fixed effects estimation equation is as follows:

$$
L n W_{i j t}=\delta_{i j}+\lambda_{t}+\sigma * X_{i j t}+\gamma * P_{j t}+\rho * Z_{j t}+\mu_{j t}+\epsilon_{i j t}
$$

where $L n W_{i j t}$ is the log monthly wage of individual $\mathrm{i}$ in province $\mathrm{j}$ in year $\mathrm{t}, \mu_{j t}$ is a province-year error component, and $\epsilon_{i j t}$ is an individual error term. The controls $\delta_{i j}$ and $\lambda_{t}$ are individual and year effects. The coefficient $\sigma$ is the parameter for individual characteristics, while the coefficient $\gamma$ is meant to capture the effect of the share of college graduated workers $\left(P_{j t}\right.$ in province $\mathrm{j}$ and year $\left.\mathrm{t}\right) . Z_{j t}$ is a vector of province characteristics that we control for. In practice, we also allow for the private return to schooling to vary over time by including the interaction of individual years of schooling and year dummies.

There are two major methodological concerns. Firstly, there may be unobservable factors that are correlated with both wages and education. A benefit of using longitudinal individual level data is that we can deal with some of the most relevant endogeneity and selectivity issues that might bias a simpler cross-sectional specification. In our case, when the non-mover sample is used (and we also control for the migration effect), individual FE estimates enable us to control for permanent unobserved individual and provincial characteristics. Taking ability for instance, we can eliminate any unobservables that may correlate with individual education and wage by assuming the unobserved ability is equally valued over time.

Secondly, time-varying factors that are correlated with overall level of human capital and wage in a given province would also bias our estimates. We deal with this problem in two ways.

On the one hand, we control for two types of time-varying factors which are well- 
documented as to possibly bias the estimates. One is referred to as migration effects, meaning that educated people move in and out due to unobservables. For example, if the wage is low in a given province, more natives (e.g. educated people) will migrate out. This labour flow would affect the college share of the destination province and in turn affect the estimated return to the college share. To control for this, we add a new variable, which is the one-year lag of the average wage in adjacent provinces, under the assumption that people are more likely to move to provinces with similar economic and cultural backgrounds to where they used to live. ${ }^{6}$

The other factor is known as the "catch-up" effect, referring to the fact that the new developing regions attract more skilled people. According to regional and urban economics, this concern involves a number of attributes, including economic factors, changes in demographics which might affect education and employment environments, etc. We first introduce two provincial level variables - "GDP per capita" and "total education expenditure" to account for economic factors. In addition, we use "provincial number of universities/colleges" and "provincial high school graduates" to proxy higher education supply and demand. People would expect that our key variable - share of college graduates - should be impacted by these kinds of factors. To calibrate more precisely the extent to which college graduates flow into the labour market and allow for a lag effect of college graduation (i.e., it is reasonable to assume that since people realize and understand the appearance of " 211 " universities, it will at least take four years for students to graduate and enter the labour market), we employ the number of college enrolments in the years that are four years before the wage is measured. ${ }^{7}$ These education variables would also help to strengthen our instruments. ${ }^{8}$

\footnotetext{
${ }^{6}$ Solo province and year dummies are not able to capture the effect of time-varying variation, such as migration, etc.

7"211" denotes Project 211. Project 211 is a project of National Key Universities and Colleges initiated in 1995 by the ministry of Education of the People's Republic of China, aiming to raise the research standards of high-level universities and cultivate strategies for socio-economic development. The fact that universities were conferred "211" title in different years depending on their quality offers us a natural variation on region* year level. We will introduce it more in section 4.2.1.

${ }^{8}$ Our instrument is the number of special status universities in each province. People might think that this variable would affect people's wages through other channels apart from the share of college graduates. For example, graduates in the province with more "211" universities will have higher human capital and wages. If high school skills (human capital) are complementary to university human capital, the high school students will also have higher productivity even if there are no externalities. These
} 
On the other hand, we use instrumental fixed effects estimates to further circumvent the potential endogeneity problem of provincial share of college graduates. Ideally, we need an instrument variable that is highly correlated with college share in a province but uncorrelated with unobserved time-varying factors that affect wage directly. In our case, we instrument the share of college graduates with the number of " 211 " universities in each province in each year.

Given that only universities with long historical reputations were considered to be listed in Project 211, one might expect that the number of "211" universities in each province is more likely to be correlated with historical and accumulative factors than contemporary market condition. ${ }^{9}$ With regard to individual characteristics, we avoid including any variables that could be endogenous to the share of college graduates, such as occupations, marital status, and so on.

The other issue is that a lot of wage information is missing. To show that there is no sample bias issue, we split the whole sample into wage-earners and non-wage-earners and find that individual variables are not significantly different between those two groups (shown in Table A.1). Table 1 presents the summary statistics.

\section{Empirical Results}

\subsection{Fixed Effects}

Table 2 presents individual fixed effects estimates. Column 1 reports the results without any provincial economic and education controls, and we find a significant negative effect of provincial college graduates share - one percentage point increase in the share of college graduates will reduce individual wages by 2.5 per cent.

In column 2, when we add controls for other relevant factors, the coefficients turn variables are expected to capture possible effects of education feature on income level.

${ }^{9}$ The establishment year is 50 years ago at least. Many universities are over 100 years old. Among 100 universities, only two of the youngest universities were established in the 1960s. The other concern might be the underlying correlation between the education feature and the economy development in a given province. The estimates would be biased upward if provinces with more " 211 " universities are also rich areas and tend to have higher wages. As addressed before, individual fixed effects model helps to deal with this problem. We will discuss it more in section 4.2.1. 
out to be insignificant, suggesting that the previous negative returns might be crowded out by some time-varying factors. For instance, the migration effect, the catch-up effect, and the time lag between getting enrolled in a university/college and actually entering the labour market, etc.

As mentioned before, we also allow for the private returns to schooling to vary over time by including the interaction of individual years of schooling and year dummies. In both columns, the private returns to schooling increased year by year from 1997 to 2009, which is in accordance with previous literature. The magnitudes of the returns also fall in the range of various research works in the existing literature.

However, the estimates in column 2 are still questionable, largely due to the endogeneity problem concerned with the key variable "share of college graduates." If some unobserved supply factors that we did not control for would also affect the labour demand side, the estimated will be biased. A reasonable guess could be the Chinese higher education expansion that took place in the later 1990s. ${ }^{10}$

\subsection{Instrumental variables fixed effects}

\subsubsection{Project " 211 "}

Project "211" is a project of National Key Universities and Colleges initiated in 1995 by the Ministry of Education of the People's Republic of China, aimed at raising the research standards of high-level universities and cultivating strategies for socio-economic development.

It is envisaged that after several years of efforts in the 21st century, approximately 100 universities and institutions of higher education would have greatly improved their quality of education, scientific research, management, and institutional efficiency. In addition, these universities and institutions will also have made remarkable progress in reforming the management system and consequently become the bases for training high-level professional manpower and solving major problems for the country's economic

\footnotetext{
${ }^{10}$ Albeit supply shocks caused by policy reform is less likely to directly bias fixed effects estimates here, people might think some other supply factors would be resulted from such education reform and then affect fixed effects results.
} 
construction and social development. The name for the project comes from an abbreviation of the 21st century and approximately 100 universities.

There are over 2,000 standard universities and higher education institutions in China, among which, 112 are "211" universities. Those "211" universities could receive extensive financial and policy support from central government. The preparation work started from around 1990, and the project ceased in 2009 so there is no new university entitled since that time.

Our instrument is hoped to be valid based on the assumption that the provincial number of "211" universities would impact the individual wages only through its effect on the share of college graduates in that province while others are equal. As the province with more "211" universities is always a more attractive place to study and work, it is quite natural that more college graduates would enter the labour market there than otherwise. Given that it reflects a stable trait of education development, the number of "211" universities is capable to instrument college share in our case.

Some people might argue that even though " 211 " universities indeed attract people, they may not immediately have an impact as college graduates enter the labour market about four years after the "211" status is conferred. However, there is no obvious time discontinuity here. As we mentioned previously, the project " 211 " is basically the recognition of accumulated and existing good reputation and high quality of certain universities and further indicates the education levels in local regions. No universities with less than 50 years of history are nominated, and most "211" universities have a history over 100 years. Therefore, the "211" status would not suddenly increase a university's fame and enrolment. Qualified universities and the corresponding province could still attract more students in the absence of Project "211" because of their long-standing advantages and reputation in the quantity and quality of higher education provided. In addition, because, when the certain university was conferred as " 211 " status in fact depends on a number of economic and political considerations, our instrument is not purely predetermined and invariant. As mentioned before, it meets the necessary requirement for a valid instrument that offers the sufficient variation in region and time dimensions. 
Therefore, we are quite confident that the appearance of "211" universities should not systematically affect other factors that influence wage level in a given province other than its college share. One advantage of using Project "211" compared to the "share of college graduates" is that although the former is also an indicator of the education level, it is a central government policy, which is much more exogenous to the local system than the latter variable. Much previous education literature has used government policy as an exogenous shock, like the compulsory schooling law, and the education expansion policy (Oreopoulos, 2006; Devereux and Fan, 2011). We claim that the Project "211" is a cleaner instrument variable than the education expansion policy. The education expansion policy means enrolment expansion to higher education institution in a general sense. Existing universities/college will recruit more students, and there will be newly established higher education institutions to absorb more higher education entrants. Nevertheless, "211" status reflects the long-run education quality and reputation and would not change students', even employees', behaviours remarkably. In this sense, Project "211" has no direct impact on the labour demand side. ${ }^{11}$ Therefore, as the education expansion might be a reason causing individual fixed effects estimates to bias downwards, Project " $211 "$ could be seen as a fairly exogenous variation in education and serves as a good instrument.

Even so, the possible underlying correlation between the education feature and the economic development in a given province would also bias our estimates. For example, provinces with more "211" universities could be wealthier areas that have higher wages. Under the assumption that region features (say, wealth) do not vary over time, individual fixed effects estimates help to deal with this problem by taking account of any timeinvariant province-specific factors that may affect our results.

\footnotetext{
${ }^{11}$ For example, to counter against the drastic labour supply increase caused by huge college degree labour entrants, governments (both central and local) developed various related policy bundles to help the newly graduated find a job, including creating new jobs, providing preferable incentives to firms that hire newly graduates, etc. This has a direct impact on the labour demand side. In contrast, Project "211" itself will not cause drastic labour supply increase like the education expansion policy, and the government will not need to develop policies to influence the demand side to deal with the huge influx of new entrants into the labour market.
} 


\subsubsection{FE-IV Estimates}

Our specifications are:

$$
\begin{aligned}
& P_{j t}=\delta_{i j}+\lambda_{t}+\sigma * X_{i j t}+\beta * N 211_{j t}+\rho * Z_{j t}+\mu_{j t}+\epsilon_{i j t} \\
& L n W_{i j t}=\delta_{i j}+\lambda_{t}+\sigma * X_{i j t}+\gamma * P_{j t}+\rho * Z_{j t}+\mu_{j t}+\epsilon_{i j t}
\end{aligned}
$$

Equation (2) presents the first stage estimation, where "N211" denotes the number of "211" universities in province $\mathrm{j}$ at year t. Equation (3) presents the second stage estimation equation. All variables are defined as before.

Table 3 reports the IV FE estimates. The first stage estimates are significantly positive with or without additional provincial controls. As one might expect, the more " 211 " universities one province has, the higher college graduates share will be in that province. Although the magnitudes decreased slightly after controlling for other economic and educational factors, the results remain quite similar by large. One additional "211" university would induce about 0.1 per cent increase in college share in a given province. 12

The coefficient of college graduates share turns out to be positively significant with and without provincial controls, suggesting that the conventional FE estimate is biased downwards. One percentage point increase in the share of college graduates will increase individual wages by about 10 per cent in the base model, and 14 per cent with further controls. This remarkable difference between the fixed effects and instrumental fixed effects estimates indicates that the variation in the college graduates share across provinces captured before is probably driven by unobserved supply factors. As we discussed in section 4.1, it could be related to the higher education expansion that took place in China in the late 1990s.

Comparing our results to the former research in related areas, we find larger educational externalities in general. Firstly, with regard to Rauch (1993), Moretti (2004), and Acemoglu and Angrist (2000) who based on their findings on U.S. data, our Chinese

\footnotetext{
${ }^{12}$ The dependent variable (share of college graduates) is measured in percentage.
} 
data give a higher estimation. One possibility is that strong competition effect driven by longer average schooling and higher education quality in developed countries would offset spillovers. In this sense, people could not benefit from working with more skilled people, the resulting education externality tends to be very low even zero. Secondly, when comparing to Liu (2007) who also uses Chinese urban data and finds about 1 per cent external returns, our estimates are still much larger. We have supportive evidence that this is mostly due to the large externalities we found in the rural areas, which will be demonstrated in the next section. In addition, the use of panel data and relevant methods could also be the reasons for such differences.

\section{Discussion}

So far, we have analysed the external returns to education using representative samples for the whole nation. In the following context, we try to split the full sample into different groups by region, gender, and education levels to see whether the external returns to education vary across individual heterogeneity.

\subsection{Education Externalities in Urban and Rural China}

Are the external returns to education different in urban and rural China? Table 4 reports the results. Liu (2007) finds that a one-year increase in city average education could increase individual earnings by between 11 per cent and 13 per cent in China. Li, Chen, and Zhang (2010) find that from 1989 to 2000, the external returns to education in urban China is about 0.64 per cent, while after 2004, it increased to about 1 per cent. Unlike them, we find no significant evidence on education externalities in urban China, suggesting that there is no solo positive or solo negative competition effect occurring. Under strong competitive working conditions in urban China, the positive spillovers are more likely to be offset by negative competition effects, ending up with zero externality. This finding may also feed into the over-educated problem associated with the higher education expansion. In addition, the signalling theory in which college degree just helps 
individuals stand out in the screening process in the labour market also offers a fair interpretation.

To date and to our knowledge, the analysis on the external returns to education for rural China is quite limited, largely due to data limitation. Therefore, our estimates hopefully provide some new evidence. In rural China, one percentage point increase in the share of college graduates in a given province would increase the individual wage by about 22 per cent. Given that education level is extraordinarily low in those areas, people might expect the increase in the proportion of educated people would bring a larger spillover relative to what would occur in urban areas.

Additionally, while signalling theory explains the zero external returns for urban areas, significant positive spillovers found in rural areas are supportive evidence for standard human capital theory, implying that it is necessary to further improve the education investment and education quality in rural areas in China.

\subsection{Education Externalities for Male and Female}

The discrimination literature has focused on investigating the gender difference in the labour market. In the education context, most researchers focus on comparing the private returns to education for males and females. For the China case, Huang (2009) provides a summary of previous research on this matter: Li (2003), Maurer-Fazio (1999), and Zhang (2005) find that females' private return to education is higher than that of males. Apart from Li (2003), all of the others use data collected from urban areas.

In this paper, we attempt to compare the external returns to education by gender. Table 5 shows the results. While there are strong positive externalities among men, there are nearly zero externalities among women.

In light of relevant literature, we try to explain this finding with different attitudes and behaviours toward competition/networking in the workplace across gender. Through a laboratory experiment, Gneezy, Niederle, and Rustichini (2003) find that women may be less effective than men in competitive environments, even if they are able to perform similarly in non-competitive environments. Niederle and Vesterlund (2007) also find 
supportive evidence for the notion that while men embrace competition, women tend to shy away from it. Therefore, compared to men, the negative competition effect for women might be so huge that it cancelled out the positive spillover effect. Shyness and fear may further prevent women from interacting and networking with colleagues so that women workers are not impacted by positive spillovers as men.

\subsection{Education Externalities for Different Education Groups}

Existing research usually finds that the marginal returns to private education decrease along with the improvement of education level. It is natural to question whether the external returns to education follow the similar pattern. Table 6 gives the estimates. We split the sample into individuals with college education or higher, who tend to be highskilled workers, and individuals with only junior high school education or even lower, who are otherwise seen as low-skilled workers in labour market.

We argue that the change in the share of college graduates in certain areas may affect workers with different skill levels differently. Moretti (2004) summarizes these with two effects: the standard imperfect substitution effect associated with a shift in college share and the spillover effect. The spillover effect is a positive effect that has been addressed extensively. The standard imperfect substitution effect related to the labour supply change has different impact on skilled and non-skilled workers.

Theoretically speaking, irrespective of the magnitude of spillover, the increase in the share of college graduates would help to increase low-skilled workers' wages. For the high-skilled workers, the final effect depends on the comparison of those two effects. If the spillover effect is stronger than the imperfect substitution effect related to labour supply, the externality coefficient would be positive. Otherwise, if the supply effect is stronger than the spillover effect, the coefficient would be negative.

As we can see from Table 6, there are strong positive externalities among low-skilled workers, whereas there is no significant externality among high-skilled workers. The possible explanation could be that the substitution effect associated with labour supply and the spillover effect cancel out each other for high-skilled workers. This finding is 
opposite to some urbanization research in under developed countries, where human capital spillovers are felt more strongly by college-educated workers than by those without college degree (Wheeler, 2001; Rosenthal and Strange, 2008), and could lead to some different inference. ${ }^{13}$ In our case, given that the increase in college graduates share is largely due to the higher education expansion policy, our results suggest that such a policy could in some sense help to decrease the wage differentials between high-skilled workers and low-skilled workers.

\section{Conclusion}

This paper provides estimates on the external returns to education in China with longitudinal data. Using CHNS, we examine how individual wages change in line with the share of college graduates in a given province in China from 1991 to 2009. The individual FE estimates of external returns to education in China appear to be zero.

Taking account of the endogeneity problem, we use the "number of '211' universities and colleges" to instrument the "share of college graduates" in a given province, and obtain sizeable positive external returns to education for the whole population. One percentage point increase in the share of college graduates would increase individual wage by about 10 per cent to 14 per cent. Thanks to the nation-wide representative sample, this finding provides justification for governments' (central and local) policy and financial investment in higher education in China. In accordance to existing findings from developed countries, increasing the overall education level would also help to increase individuals' earnings in China.

Besides the main findings, we also have three further important insights into the role of education by looking at individual heterogeneity. Firstly, we find nearly zero education externalities in urban areas, but large positive externalities in rural areas, providing evidence for further improving the education investment and education quality in rural China. This evidence also implies some over-educated problems in urban areas, which means that urban dwellers have to face severe competition in labour market and

\footnotetext{
${ }^{13}$ Restricting samples to urban areas still generates spillover effects for more educated workers.
} 
also tend to suffer from the signalling effect. The signalling effect posits that college does not further education but just helps workers with a college degree to identify themselves from those without one.

Secondly, gender differences also exist in the external returns to education in China. Men workers gain from networking with other educated ones whereas women do not.

Finally, but perhaps most interestingly, we find strong positive externalities among low-skilled workers, but no significant externalities among high-skilled workers. This intriguing comparison indicates that education spillovers in some sense can help to decrease the wage differentials between high-skilled and low-skilled workers. 


\section{References}

Acemoglu, Daron. 1996. "A Microfoundation for Social Increasing Returns in Human Capital Accumulation." Quarterly Journal of Economics, 111(3): 779-804.

Acemoglu, Daron, and Angrist, Joshua. 2005. "How Large Are Human-Capital Externalities?

Evidence from Compulsory Schooling Laws." NBER/Macroeconomics Annual (MIT Press), 15(1): 9-59.

Devereux, Paul. J. and Fan, Wen. 2011. "Earnings returns to the British education expansion. " Economics of Education Review, 30:1153-1166.

Gneezy, Uri; Niederle, Muriel, and Rustichini, Aldo. 2003. "Performance in Competitive Environments: Gender Differences." Quarterly Journal of Economics, 118(3): 1049-74. Huang, Zhiling, and Yao, Xianguo. 2009. "The Gender difference on the Returns to Education" World Economy 7.

Kirby, Simon, and Riley, Rebecca. 2008. "The External Returns to Education: UK Evidence Using Repeated Cross-Sections." Labour Economics 15(4): 619-30.

Li, Haizheng. 2003. "Economic Transition and Returns to Education in China." Economics of Education Review, 22(3): 317-28.

Li, Xiaoying; Chen, Guanghan, and Zhang Yingwu. 2010. "Estimating the External Returns to Higher Education in Urban China" World Economic Paper 1.

Liu, Zhiqiang. 2007. "The External Returns to Education: Evidence from Chinese Cities." Journal of Urban Economics, 61(3): 542-64.

Lucas Jr, Robert E. 1998. "On the Mechanics of Economic Development." |em Journal of Monetary Economics, 22(1): 3-42.

Marshall, Alfred. 1961. Principles of Economics. London: MacMillan.

Maurer-Fazio, Margaret. 1999. "Earnings and Education in China's Transition to a Market Economy Survey Evidence from 1989 and 1992." China Economic Review, 10(1): $17-40$.

Moretti, Enrico. 2004a. "Estimating the Social Return to Higher Education: Evidence from Longitudinal and Repeated Cross-Sectional Data." Journal of Econometrics, 121: 175-212. 
Moretti, Enrico. 2004b. "Workers' Education, Spillovers, and Productivity: Evidence from Plant-Level Production Functions." The American Economic Review, 94(3): 65690.

Niederle, Muriel, and Vesterlund, Lise. 2007. "Do Women Shy Away from Competition? Do Men Compete Too Much?" Quarterly Journal of Economics, 122(3): 1067-101.

Oreopoulos, Philip. 2006. "Estimating Average and Local Average Treatment Effects of Education When Compulsory Schooling Laws Really Matter." American Economic Review, 96(1): 152-75.

Rauch, James E. 1993. "Productivity Gains from Geographic Concentration of Human Capital: Evidence from the Cities." Journal of Urban Economics 34: 380-400.

Rosenthal, Stuart S. and Strange, William. 2008. "The Attenuation of Human Capital Spillovers. " Journal of Urban Economics 64: 373-389.

Wheeler, Christopher H. 2001. "Search, Sorting and Urban Agglomeration. " Journal of Labor Economics 19(4): 879-899.

Zhang, Junsen; Zhao, Yaohui; Park, Albert and Song, Xiaoqing. 2005. "Economic Returns to Schooling in Urban China, 1988 to 2001." Journal of Comparative Economics 33(4): 730-52. 


\section{Figures}

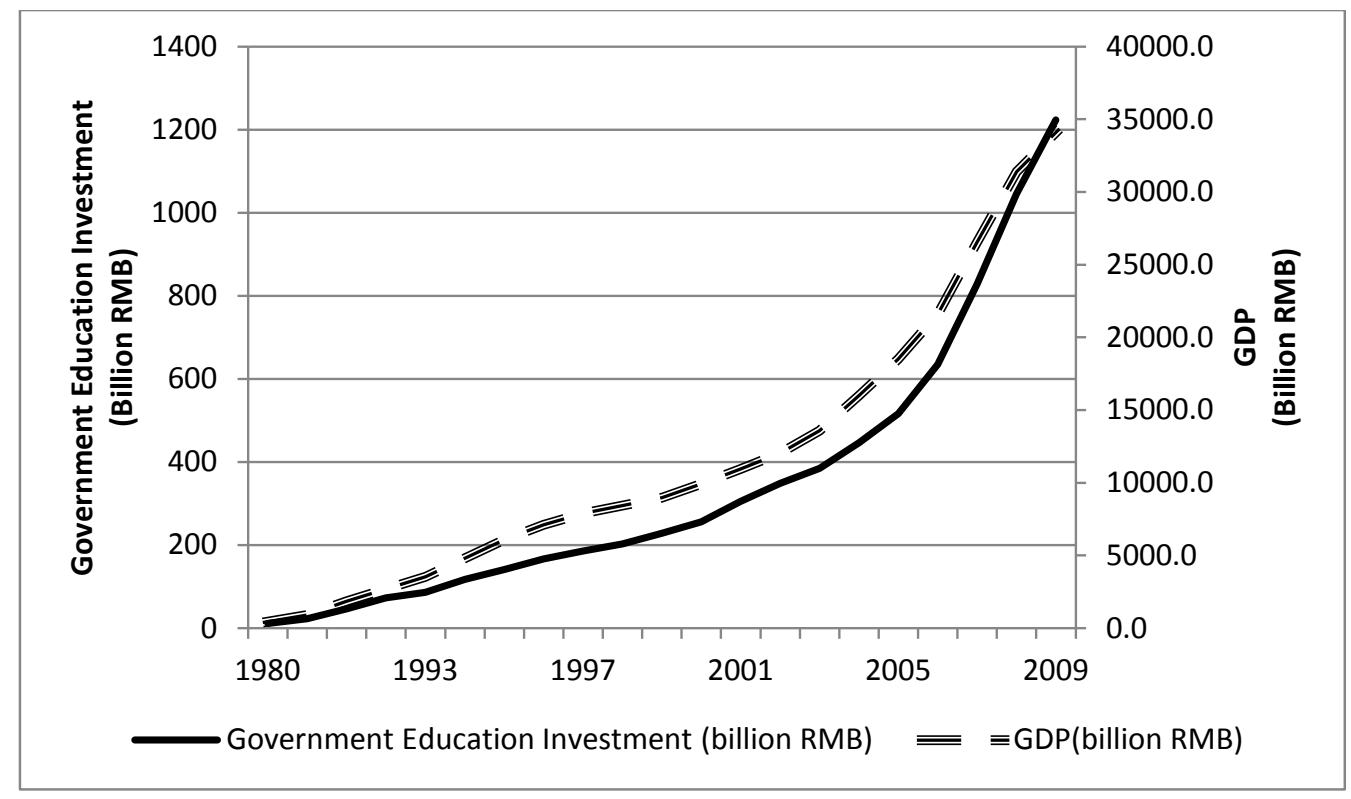

Figure 1: GDP and Government Educational Investment in China (1980-2009)

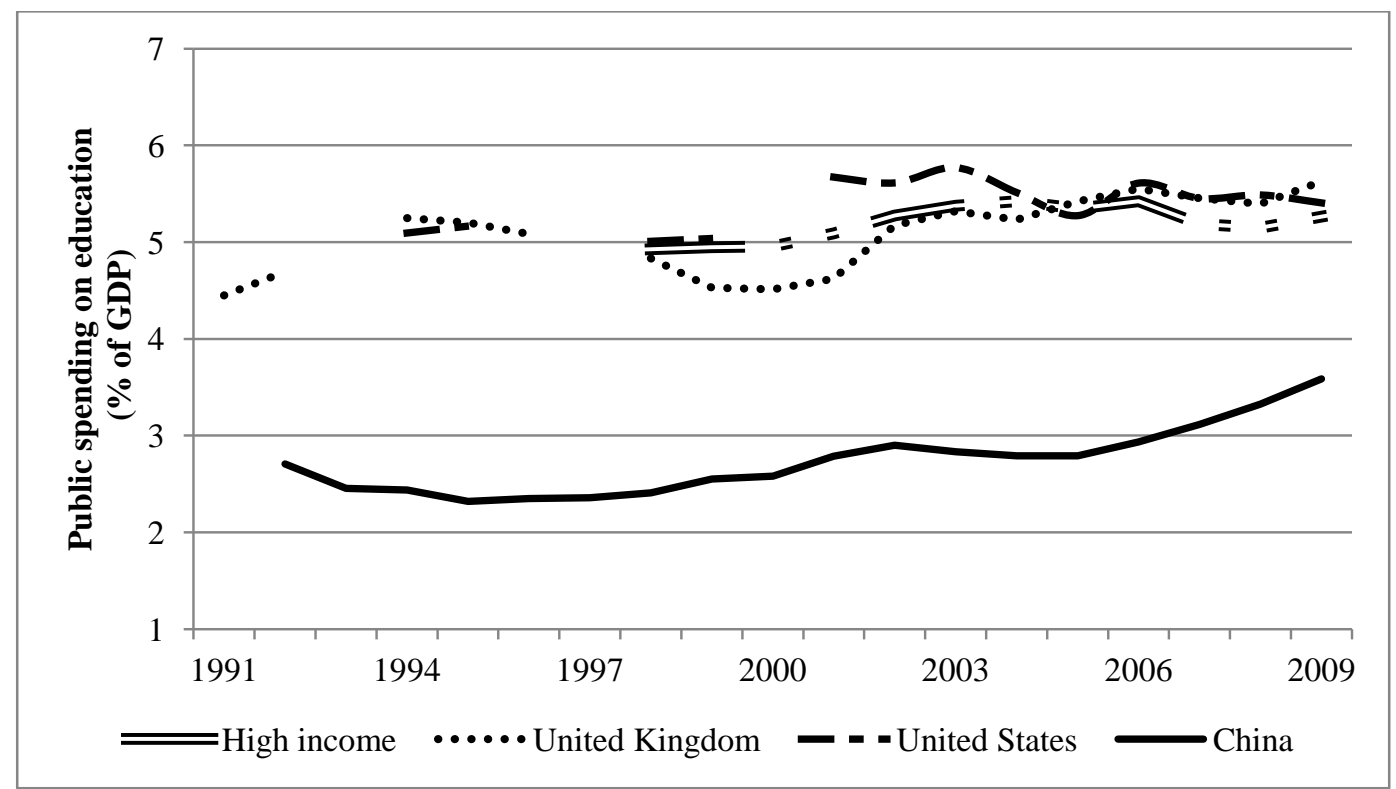

Figure 2: The Proportion of Public Spending on Education in GDP(1991-2009) 


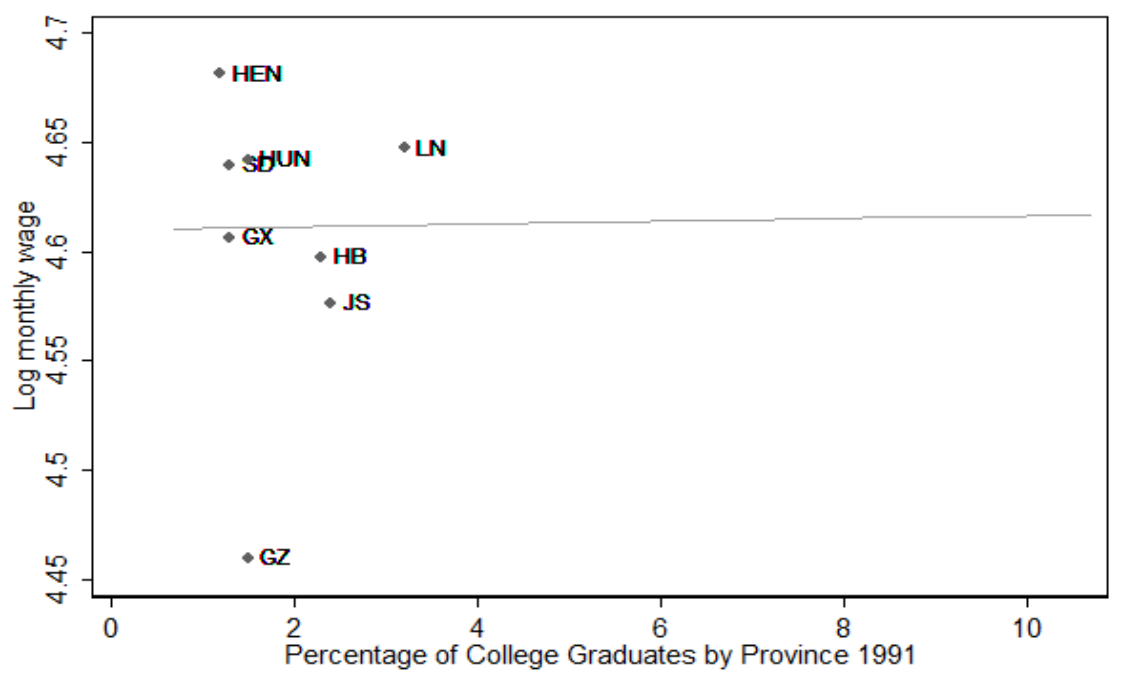

Figure 3: Correlation between Log Monthly Wage and Share of College Graduates (1991)

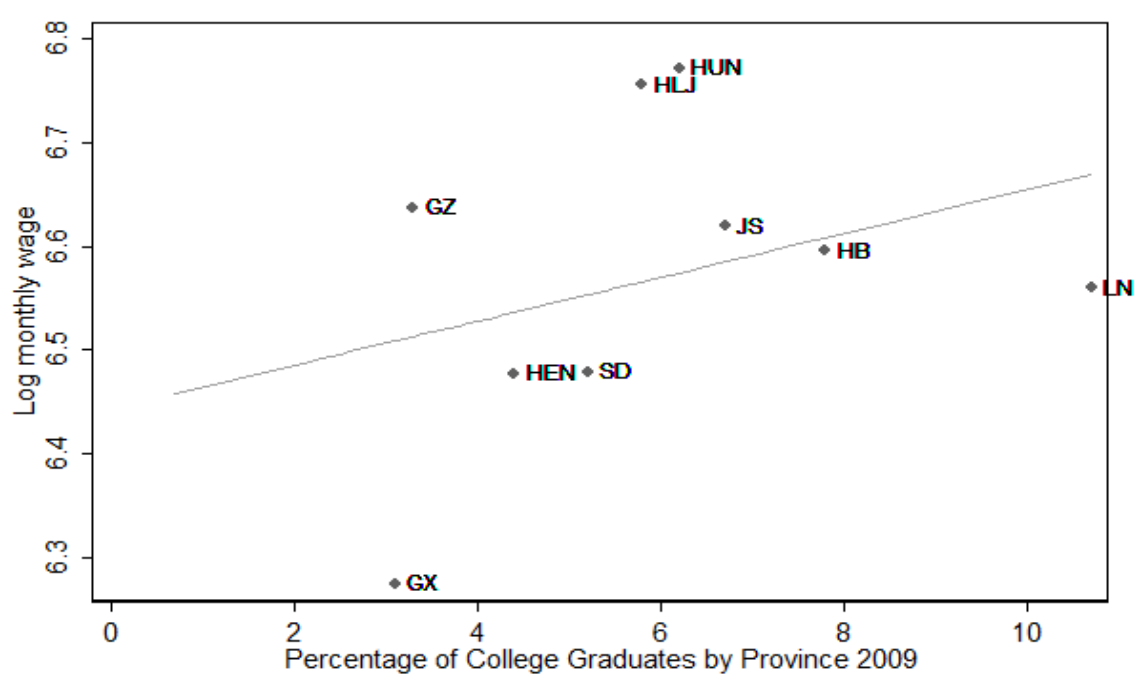

Figure 4: Correlation between Log Monthly Wage and Share of College Graduates (2009) 


\section{Tables}

Table 1: Summary Statistics

\begin{tabular}{lccc}
\hline Variable & N & Mean & Std. Dev. \\
\hline Individual level & & & \\
Log(monthly wages) & 12772 & 6.09 & 1.06 \\
Individual years of schooling & 38931 & 8.78 & 3.54 \\
Age & 40488 & 38.63 & 10.54 \\
Female & 40491 & 0.52 & 0.5 \\
Survey year & 40560 & 2000.88 & 6.05 \\
\hline Province level & & & \\
Share of college graduates (\%) & 40560 & 3.8 & 2.17 \\
Number of "211" Universities & 40560 & 2.54 & 2.93 \\
GDP per capita (in thousand Yuan) & 40560 & 9.67 & 8.48 \\
Lag log(annual average wage) of adjacent provinces & 40560 & 8.87 & 0.82 \\
Provincial education expenditure (in billion Yuan) & 40560 & 20.06 & 17.52 \\
Number of universities and colleges & 40560 & 62.96 & 27.88 \\
Number of high school graduates (in thousands) & 40560 & 232.28 & 177.04 \\
University and college enrolments (in thousands) & 40560 & 83.02 & 78.85 \\
\hline
\end{tabular}


Table 2: Fixed Effects Estimates of External Returns to Education (1991-2009)

\begin{tabular}{|c|c|c|}
\hline $\mathrm{Y}=\mathrm{LOG}(\mathrm{MONTHLY}$ WAGE) & [1] & {$[2]$} \\
\hline Share of College Graduates & $\begin{array}{c}-.025 * * * \\
(.009)\end{array}$ & $\begin{array}{l}-.014 \\
(.010)\end{array}$ \\
\hline Age & $\begin{array}{c}.355^{* * *} \\
(.088)\end{array}$ & $\begin{array}{c}.288^{* * * *} \\
(.092)\end{array}$ \\
\hline Age sq./100 & $\begin{array}{l}-.013 \\
(.009)\end{array}$ & $\begin{array}{l}-.014 \\
(.009)\end{array}$ \\
\hline Years of edu*1997 & $\begin{array}{c}.007 \\
(.006)\end{array}$ & $\begin{array}{l}.007 \\
(.006)\end{array}$ \\
\hline Years of edu*2000 & $\begin{array}{c}.034^{* * *} \\
(.006)\end{array}$ & $\begin{array}{c}.034^{* * * *} \\
(.006)\end{array}$ \\
\hline Years of edu*2004 & $\begin{array}{c}.067^{* * *} \\
(.007)\end{array}$ & $\begin{array}{c}.063^{* * *} \\
(.007)\end{array}$ \\
\hline Years of edu*2006 & $\begin{array}{c}.083^{* * *} \\
(.007)\end{array}$ & $\begin{array}{c}.079^{* * * *} \\
(.007)\end{array}$ \\
\hline Years of edu*2009 & $\begin{array}{c}.095^{* * *} \\
(.007)\end{array}$ & $\begin{array}{l}.091^{* * *} \\
(.007)\end{array}$ \\
\hline \multicolumn{3}{|l|}{ Provincial Characteristics } \\
\hline GDP per capita & & yes \\
\hline Lag $\log$ (annual wage) of adjacent province & & yes \\
\hline Provincial education expenditure & & yes \\
\hline Number of universities and colleges & & yes \\
\hline Number of high school graduates & & yes \\
\hline University and college 4-years ago enrolments & & yes \\
\hline Observations & 11,893 & 11,893 \\
\hline
\end{tabular}

Note: (1) All specifications also include year-dummies.

Robustness standard errors in parentheses allow for clustering by individual. (3)* denotes the significance level, with *** $\mathrm{P}<0.01$, ** $\mathrm{p}<0.05,{ }^{*} \mathrm{P}<0.1$. 
Table 3: FE-IV Estimates of the External Returns to Education (1991-2009)

\begin{tabular}{|c|c|c|c|c|}
\hline & \multicolumn{2}{|c|}{ First Stage } & \multicolumn{2}{|c|}{ IV } \\
\hline & \multicolumn{2}{|c|}{$\mathrm{Y}=$ college share } & $\mathrm{Y}=\mathrm{L}$ & nthly wage) \\
\hline Instrument : No. of "211" Universities & $\begin{array}{c}.117^{* * *} \\
(.002)\end{array}$ & $\begin{array}{c}.085 * * * \\
(.002)\end{array}$ & & \\
\hline Share of College Graduates & & & $\begin{array}{l}.098^{*} \\
(.051)\end{array}$ & $\begin{array}{c}.138^{* * *} \\
(.049)\end{array}$ \\
\hline Observations & 38,867 & 38,867 & 8,456 & 8,456 \\
\hline \multicolumn{5}{|l|}{ Provincial Characteristics } \\
\hline GDP per capita & & yes & & yes \\
\hline Lag $\log$ (annual wage) of adjacent province & & yes & & yes \\
\hline Provincial education expenditure & & yes & & yes \\
\hline Number of universities and colleges & & yes & & yes \\
\hline Number of high school graduates & & yes & & yes \\
\hline University and college 4-years ago enrolments & & yes & & yes \\
\hline
\end{tabular}

Note: (1) All specifications also include age, age-squared, year-dummies, interactions between individual education and year dummies and provincial characteristics mentioned in text. (2) Robustness standard errors in parentheses allow for clustering by individual. (3) Individual fixed effects are included in the first stage regression. (4) * denotes the significance level, with $* * * \mathrm{P}<0.01,{ }^{* *} \mathrm{p}<0.05, * \mathrm{P}<0.1$. 
Table 4: FE and FE-IV Estimates of External Returns to Education by Region (19912009)

\begin{tabular}{lcccc}
\hline & \multicolumn{2}{c}{ Urban } & \multicolumn{2}{c}{ Rural } \\
\hline & FE & FE-IV & FE & FE-IV \\
First Stage & & & & \\
Number of "211" Universities & & $.065^{* * *}$ & & $.093^{* * *}$ \\
& & $(.003)$ & & $(.002)$ \\
Observations & & 12,460 & & 26,407 \\
\hline Share of College Graduates & -.018 & .043 & -.007 & $.223^{* * *}$ \\
& $(.016)$ & $(.083)$ & $(.016)$ & $(.062)$ \\
Observations & 5,799 & 4,301 & 6,094 & 4,155 \\
\hline
\end{tabular}

Note: (1) All specifications also include age, age-squared, yeardummies, interactions between individual education and year dummies and provincial characteristics mentioned in text. (2) Robustness standard errors in parentheses allow for clustering by individual. (3) Individual fixed effects are included in the first stage regression. (4)* denotes the significance level, with $* * * \mathrm{P}<0.01, * * \mathrm{p}<0.05, * \mathrm{P}<0.1$. 
Table 5: FE and FE-IV Estimates of External Returns to Education by Gender (19912009)

\begin{tabular}{lcccc}
\hline & \multicolumn{2}{c}{ Men } & \multicolumn{2}{c}{ Women } \\
\hline & FE & FE-IV & FE & FE-IV \\
First Stage & & & & \\
Number of "211" Universities & & $.091^{* * *}$ & & $.080^{* * *}$ \\
& & $(.002)$ & & $(.002)$ \\
Observations & & 18,849 & & 20,018 \\
\hline Share of College Graduates & .008 & $.177^{* * *}$ & $-.046^{* * *}$ & .06 \\
& $(.014)$ & $(.063)$ & $(.015)$ & $(.076)$ \\
Observations & 6,941 & 5,127 & 4,952 & 3,329 \\
\hline
\end{tabular}

Note: (1) All specifications also include age, age-squared, year-dummies, interactions between individual education and year dummies and provincial characteristics mentioned in text. (2) Robustness standard errors in parentheses allow for clustering by individual. (3) Individual fixed effects are included in the first stage regression. $(4) *$ denotes the significance level, with ${ }^{* * *} \mathrm{P}<0.01,{ }^{* *} \mathrm{p}<0.05, * \mathrm{P}<0.1$. 
Table 6: FE and FE-IV Estimates of External Returns to Education by Education Levels (1991-2009)

\begin{tabular}{lcccc}
\hline & \multicolumn{2}{c}{$\begin{array}{c}\text { Compulsory schooling } \\
\text { or below }\end{array}$} & \multicolumn{2}{c}{$\begin{array}{c}\text { Some college } \\
\text { and College }+\end{array}$} \\
\hline & FE & FE-IV & FE & FE-IV \\
First Stage & & $.841^{* * *}$ & & $.086^{* * *}$ \\
Number of "211" Universities & & $(.002)$ & & $(.006)$ \\
Observations & & 27,192 & & 3,995 \\
\hline Share of College Graduates & .010 & $.131^{* *}$ & $-.047^{* * *}$ & -.021 \\
& $(.017)$ & $(.061)$ & $(.016)$ & $(.128)$ \\
Observations & 5,642 & 3,449 & 3,020 & 2,562 \\
\hline
\end{tabular}

Note: (1) All specifications also include age, age-squared, year-dummies, interactions between individual education and year dummies and provincial characteristics mentioned in text. (2) Robustness standard errors in parentheses allow for clustering by individual. (3) Individual fixed effects are included in the first stage regression. (4) ${ }^{*}$ denotes the significance level, with ${ }^{* * *} \mathrm{P}<0.01$, ** $\mathrm{p}<0.05,{ }^{*} \mathrm{P}<0.1$. 


\section{Appendix}

Table A.1: Summary Statistics for Wage-earners and Non-wage-earners Sample

\begin{tabular}{lcccc}
\hline & \multicolumn{3}{c}{ Wage Sample } & \multicolumn{2}{c}{ Non-wage Sample } \\
\hline & Mean & (SD) & Mean & (SD) \\
Individual Years of Schooling & 10.73 & 3.22 & 7.92 & 3.32 \\
Age & 37.39 & 9.47 & 39.2 & 10.95 \\
Female & 0.42 & 0.49 & 0.56 & 0.5 \\
Sample Size & \multicolumn{2}{c}{12,717} & & 27,788 \\
\hline
\end{tabular}

